\title{
Study of the Influence of $\beta$-Radiation on the Properties and Mineralization of Different Starch-Based Biomaterials
}

\author{
A. L. Oliveira, ${ }^{1,2}$ J. F. Mano, ${ }^{1,2}$ J. San Román, ${ }^{3}$ R. L. Reis ${ }^{1,2}$ \\ 1 3B's Research Group - Biomaterials, Biodegradables \& Biomimetics, University of Minho, Campus de Gualtar, 4710-057, \\ Braga, Portugal \\ ${ }^{2}$ Department of Polymer Engineering, University of Minho, Campus de Azurém, 4800-058 Guimarães, Portugal \\ ${ }^{3}$ CSIC, Institute of Polymer Science and Technology, Juan de la Cierva, 3, 28006 Madrid, Spain
}

Received 8 June 2004; revised 29 October 2004; accepted 29 October 2004

Published online 19 May 2005 in Wiley InterScience (www.interscience.wiley.com). DOI: 10.1002/jbm.b.30260

\begin{abstract}
In this work, the effects of $\beta$-radiation are assessed, for the first time, on starchbased biodegradable polymers, with the aim of using it as an alternative sterilization process to the previously studied sterilization methods. Different doses of radiation were used in order to investigate the possibility of using this sterilization technique as a treatment to tailor the surface and bulk properties (namely mechanical) of these polymers. The as-treated substrates were characterized by water-uptake measurements and contact angle $(\theta)$ measurements. The mechanical properties of the materials were characterized by tensile tests by means of ultimate tensile strength (UTS) and strain at break $(\epsilon r)$. The fracture of the surfaces was observed by scanning electron microscopy (SEM). Dynamic mechanical analysis (DMA) was also used to characterize the viscolelastic behavior of the irradiated materials. The main effect of sterilization with $\beta$-radiation over the starch-based polymers seems to be a surface modification by an increase of the hydrophilicity. Nevertheless, because $\beta$-radiation did not significantly affect the mechanical properties, it can be regarded as an effective way of modifying the surface for applications were more hydrophilic surfaces are desirable. () 2005 Wiley Periodicals, Inc. J Biomed Mater Res Part B: Appl Biomater 74B: 560-569, 2005
\end{abstract}

Keywords: $\quad \beta$-radiation; starch-based biodegradable polymers; dynamic mechanical analysis (DMA); sterilization

\section{INTRODUCTION}

The increased demands placed on biomaterials for both currently approved and novel emerging applications continue to stimulate the interest in improving the performance of existing medical-grade polymers and developing new polymeric systems. Starch-based polymers present an enormous potential to be widely used in the biomedical and the environmental fields, as they are biodegradable, inexpensive (when compared to other biodegradable polymers) from renewable origin, and available in large quantities. ${ }^{1-3}$ On the other hand, they exhibit a biocompatible behavior already demonstrated by in vitro ${ }^{4-6}$ and in vivo studies. ${ }^{6}$ Indeed, this class of materials has recently been proposed for a wide range of biomedical applications including bone replacement/fixation

Correspondence to: A. L. Oliveira (e-mail: analeite@dep.uminho.pt)

Contract grant sponsor: Portuguese Foundation for Science and Technology (FCT); contract grant number: SFRH/BD/10956/2002

Contract grant sponsor: Portuguese Foundation for Science and Technology (FCT) POCTI and/or FEDER programs

(C) 2005 Wiley Periodicals, Inc. and filling of bone defects, ${ }^{7,8}$ hydrogels for drug delivery,,${ }^{9,10}$ or bone cements. ${ }^{11}$ Furthermore, starch-based polymers can also be converted into complex geometries with interesting mechanical properties, by using standard equipment developed for the processing of synthetic polymers ${ }^{12,13}$ or by different innovative methodologies. ${ }^{14,15}$ These constructs are being proposed to be used as temporary scaffolds for several tissue engineering approaches. ${ }^{12-15}$

Starch-based systems, under consideration for being used in tissue replacement/fixation or as tissue engineering scaffolds, must exhibit mechanical properties that match, as close as possible, those of human bone. This should be associated to a degradation kinetics adequate for tissue healing that is to be replaced or fixed. ${ }^{12,16,17}$ In addition, by the incorporation of bonelike inorganic fillers, such as hydroxyapatite $(\mathrm{HA})^{18-22}$ or bioactive glasses, ${ }^{23,24}$ it is possible to develop bioactive degradable composites with an interesting range of mechanical properties. It was also reported ${ }^{18,25}$ that the physical properties of those materials can be further optimized by controlling the morphologic developments within the molds by using nonconventional processing routes. When coated 
with a bonelike apatite layer, biodegradable polymers also have a great potential to be used as bone-repairing materials because they can exhibit not only mechanical properties analogous to the natural bone but also a bioactive character. $^{26-29}$

No matter how optimized a biomaterial is, it will always have to resist the final step of sterilization before implantation. Sterilizability and storage stability are necessary for any material used in a medical application. ${ }^{30,31}$ It is then important to investigate the stability of a material after sterilization and to determine the most convenient sterilization methodology. Furthermore, sterilization can be used as a treatment to improve mechanical properties (crosslinking) and tailor the surface properties of polymeric biomaterials. ${ }^{32}$ In this context, the effects of ethylene oxide (EtO) sterilization over the properties of starch-based polymers were already studied in previous works, namely its influence on the formation of a biomimetic coating. ${ }^{33,34}$ Nevertheless, its attractiveness is decreasing due to the toxicity and flammability of the EtO gas, ${ }^{35}$ as well as some concerns and lobbying strategies related to possible cancer-inducing effects. ${ }^{36}$ On the other hand, sterilization by high-energy radiation has the advantages of high efficiency, negligible thermal effects, high penetration, and being a chemically cleaner process. ${ }^{31,37} \gamma$-radiation sterilization is widely studied for application with biodegradable polymeric biomaterials. ${ }^{38,39}$ One side effect of $\gamma$-rays is on the bulk properties of the polymers, due to the high penetrability of this type of radiation. The influence of $\gamma$-radiation on starch has been studied in the past years with regard to the agricultural and food chemistry fields. It is well known that this type of radiation induces physicochemical transformations in starch granules. ${ }^{40}$ The breakdown of glycoside bond and decomposition of macromolecules accompanied by the creation of macromolecules with smaller chains is the primary reaction occurring under the influence of irradiation. ${ }^{41}$ Apart from these effects, small molecular products are created, caused by glycoside bond destruction at chains termini. ${ }^{42}$ A decrease in both crystalline phase content and the ordered distributions of amylose and amylopectin macromolecules in starch granules, connected with these chemical changes, was observed by authors such as Ciesla and colleagues. ${ }^{43}$

Recent advances in electron beam technology have made this mode of sterilization a worthy competitor to the traditional $\gamma$ processing. Increased available energy, compact design, improved reliability, and the absence of a source that steadily depletes with time are some of the reported advantages. ${ }^{44}$ Although the primary event of interaction with matter is different between $\gamma$-radiation and electrons, the major interaction is still Compton scattering for both cases. It is mainly the shower of secondary electrons that initiates the ionization events that triggers numerous chemical reactions, many of which lead to oxidative degradation. Although the main interaction with matter is basically the same for $\gamma$ and high-energy electrons, differences between the two modes remain. The penetration of $\beta$-radiation is lower than in the case of $\gamma$-radiation, which will be advantageous for preserv- ing the mechanical bulk properties of materials, ${ }^{44}$ for example, biodegradable polymers.

This preliminary work aims at evaluating the effects of $\beta$-radiation on both the mechanical performance and degradation behavior of starch-based biodegradable polymers, as well as to assess the potential of $\beta$-radiation as alternative sterilization method to previously studied sterilization methods. Furthermore, different radiation doses were also tentatively investigated as possible routes for tailoring the surface and bulk properties (namely mechanical) of these starchbased biodegradable polymers.

\section{MATERIALS AND METHODS}

\section{Materials}

The studied materials included injection-molded blends of starch with: (i) poly(ethylene vinyl alcohol) (SEVA-C, 50/50 wt \%), (ii) cellulose acetate (SCA, 50/50 wt \%), and (iii) polycaprolactone (SPCL, 30/70 wt \%). The materials were injection molded in a Klockner Desma FM-20 (Fridingen/ Donau, Germany), in order to produce standard ASTM tensile dumbbell samples with a cross-section of $2 \times 4 \mathrm{~mm}^{2}$. These materials were subjected to 25,50 , and $100 \mathrm{kGy}$ doses of $\beta$-radiation according to the standard procedure of IonMed Esterilizacion, S.A. (Madrid, Spain), using a Rhotron TT2 electron accelerator $(10 \mathrm{MeV})$.

\section{Mechanical Properties}

Tensile tests were performed in order to evaluate the influence of $\beta$-radiation doses on the mechanical behavior of the starch-based materials. The samples were tested in order to determine the modulus of elasticity (e-modulus), the ultimate tensile strength (UTS), the strain at break $\left(\epsilon_{\mathrm{b}}\right)$ and the energy to break point $\left(\mathrm{U}_{\mathrm{b}}\right)$. Five samples were tested for each condition. These tests were performed on an Instron 4505 universal mechanical testing machine (Canton, MA, U.S.A.) fitted with an Instron 2703 10-mm gauge length resistive extensometer under controlled conditions $\left(23^{\circ} \mathrm{C}, 55 \% \mathrm{RH}\right)$. The crosshead speed was $5 \mathrm{~mm} / \mathrm{min}$ until $1 \%$ strain was reached (for more precision); the speed was then increased to $50 \mathrm{~mm} / \mathrm{min}$ until fracture.

\section{SEM Analysis of Tensile Fracture Surfaces}

After performing tensile tests on the studied materials, the morphology of the obtained surface fractures was observed by scanning electron microscopy (SEM), in a Leica Cambridge S360 (Cambridge, UK) or in a HITACHI S4100 (Tokyo, Japan). All the samples were previously gold-coated in a Sputter Jeol JFC 1100 equipment (Tokyo, Japan).

\section{DMA Analysis}

The investigation of the viscoelastic properties of biodegradable polymeric-based systems may be of great interest because one can not only simulate the physiological dynamical 
loading, but can also access relevant fundamental information at the molecular level, both from a structural and dynamic perspective. In a more practical point of view, besides the typical quasistatic mechanical properties (elastic modulus or ultimate strength and strain), an implantable biomaterial should exhibit adequate rheological properties that should preferentially match those of the tissues with which it will be in contact. The dynamic mechanical analysis technique (DMA) is a very suitable tool to investigate the viscoelastic properties of polymers in a wide range of temperatures and frequencies. ${ }^{45}$

DMA characterization was performed in order to evaluate the possible effects of $\beta$-radiation on the viscoelastic behavior of different starch-based materials. For this study, injection-molded samples were shaped into specimens of $5 \times 20$ $\mathrm{mm}$ and tested under a three-point bending loading scheme, using a PerkinElmer DMA7e apparatus (Norwalk, CT) with controlled cooling accessory. High purity helium was used as a purge gas, increasing the thermal conductivity inside the furnace. Temperature was scanned from -30 to $130^{\circ} \mathrm{C}$ at $4^{\circ} \mathrm{C} / \mathrm{min}$ at a frequency of $1 \mathrm{~Hz}$. The specimens were placed over a bending platform with a $15-\mathrm{mm}$ span and a $5-\mathrm{mm}$ knife-edge probe tip that provided the mechanical excitation: a static stress of $0.36 \mathrm{MPa}$ for SEVA-C and SCA and 0.12 MPa for SPCL superimposed to a dynamic stress of $0.30 \mathrm{MPa}$ for SEVA-C and SCA and 0.10 MPa for SPCL. Those stress values were sufficiently small to assure that the mechanical response of the specimens is within the linear viscoelastic regime. A minimum of three samples were analyzed and averaged for each condition.

\section{Studies in Wet Conditions}

Studies in wet conditions are of a great importance for any degradable biomaterial ${ }^{17}$ because when implanted, it will inevitably be in the presence of the body fluids that will diffuse into the bulk of the polymer as degradation takes place.

For water-uptake measurements, all samples were weighed before immersed in distilled water (at room temperature) and every $2 \mathrm{~h}$, during the first $12 \mathrm{~h}$ of immersion. After that period, weights were recorded every $24 \mathrm{~h}$ until the end of the experiment time (7 days). The samples were carefully removed from the water-containing flasks and immediately weighed for determination of wet weight as a function of the immersion time. Water-uptake is given by:

$$
\text { Water absorbed }=\left[\left(m_{\mathrm{f}}-m_{\mathrm{i}}\right) / m_{\mathrm{i}}\right] \times 100
$$

where $m_{\mathrm{i}}$ is the initial weight of the sample and $m_{\mathrm{f}}$ is the sample weight after a given time of immersion.

The degradation behavior was assessed after several prefixed aging periods $(0,3,7,15$, and 60 days) for materials before and after increasing doses of $\beta$-radiation, in an isotonic saline solution $(\mathrm{NaCl} 0.154 \mathrm{M})$. For each period, three samples were used. At the end of each aging period, the samples were removed from the solution and then dried up to exhaustion $\left(6\right.$ days at $\left.60^{\circ} \mathrm{C}\right)$, in order to determine the dry weight loss, which is given by:

$$
\% \text { Weight loss }=\left[\left(m_{\mathrm{i}}-m_{\mathrm{d}}\right) / m_{\mathrm{i}}\right] \times 100
$$

where $m_{\mathrm{i}}$ is the initial weight of the sample and $m_{\mathrm{d}}$ is the sample dry weight after a given time of immersion.

\section{Contact-angle measurements}

In previous works, SEVA-C has demonstrated to be a quite hydrophilic substrate. ${ }^{17,27}$ In this work, contact-angle measurements were performed on all the starch-based polymer samples before and after increasing doses of $\beta$-radiation in order to detect any eventual modification in the surface of the material. Contact-angle measurements were obtained by the sessile drop method using a standard contact angle apparatus (Krüss, Hamburg, Germany). The measurements were performed with the aid of an image analysis system (G2/G40) installed in the apparatus. Duplicate measurements were recorded for each drop deposition. The average values were recorded after $5 \mathrm{~s}$ of the drop deposition (settling time). Ten average values were recorded for each condition and a final average value was calculated. All the measurements were made at room temperature and the probe liquid was distilled water.

\section{RESULTS AND DISCUSSION}

\section{Mechanical Properties}

The effect of $\beta$-radiation over the mechanical properties and chemical structure of starch polymers (SEVA-C, SPCL, and SCA) was studied. All the materials were subjected to different doses of $\beta$-radiation: 25,50 , and $100 \mathrm{kGy}$. Tensile tests were performed in order to evaluate inevitable mechanical properties changes resulting from the sterilization process. Table I presents the tensile results as function of increasing radiation doses.

The tensile test results show that the mechanical properties of the starch-based blends such as SEVA-C and SCA appear to be less affected by $\beta$-radiation. However, $\beta$-radiation seems to affect SPCL more extensively. In general, $\beta$-radiation affects the stiffness, strength, and ductility in different ways for each material. For SEVA-C, the decrease in stiffness and ductility and the simultaneous increase in strength may be an indication of a possible decrease in crystallinity. Because sterilization with EtO has been already tested for this particular material, it is interesting to compare the previously obtained results with those obtained here. Data for the mechanical properties of this material after exposure to EtO sterilization, as reported previously, ${ }^{33}$ indicated that some degradation took place. A decrease in the modulus of $9 \%$ and $29 \%$, after one and two consecutive sterilization cycles, respectively, were observed, as well as a concomitant decrease in crystallinity. The gas absorbed in the structure was re- 
TABLE I. Tensile Results for Samples Subjected to Different Doses of $\boldsymbol{\beta}$ Radiation

\begin{tabular}{|c|c|c|c|c|c|}
\hline Material & $\begin{array}{l}\text { Dose } \\
(\mathrm{kGy})\end{array}$ & $\begin{array}{l}\text { Stiffness E-modulus } \\
(\mathrm{GPa})\end{array}$ & $\begin{array}{c}\text { Strength UTS } \\
(\mathrm{MPa})\end{array}$ & $\begin{array}{c}\text { Ductility } \varepsilon_{\mathrm{b}} \\
(\%)\end{array}$ & $\begin{array}{c}\text { Toughness } \mathrm{U}_{\mathrm{b}} \\
(\mathrm{J})\end{array}$ \\
\hline \multirow[t]{3}{*}{ SEVA-C } & 0 & $1.89 \pm 0.34$ & $33.2 \pm 0.9$ & $52.3 \pm 1.8$ & $1.03 \pm 0.032$ \\
\hline & 50 & $1.76 \pm 0.06$ & $36.3 \pm 0.6$ & $31.1 \pm 0.5$ & $0.67 \pm 0.002$ \\
\hline & 100 & $1.64 \pm 0.07$ & $37.3 \pm 0.4$ & $23.8 \pm 5.8$ & $0.51 \pm 0.124$ \\
\hline \multirow[t]{2}{*}{ SCA } & 0 & $1.01 \pm 0.11$ & $26.1 \pm 0.8$ & $11.9 \pm 1.1$ & $0.21 \pm 0.01$ \\
\hline & 100 & $1.45 \pm 0.14$ & $34.8 \pm 2.3$ & $6.8 \pm 0.9$ & $0.13 \pm 0.01$ \\
\hline \multirow[t]{4}{*}{ SPCL } & 0 & $0.22 \pm 0.03$ & $24.1 \pm 1.6$ & $641.0 \pm 10.8$ & $8.36 \pm 0.24$ \\
\hline & 25 & $0.33 \pm 0.04$ & $22.1 \pm 0.5$ & $606.4 \pm 16.8$ & $7.50 \pm 0.34$ \\
\hline & 50 & $0.30 \pm 0.03$ & $18.4 \pm 1.5$ & $574.9 \pm 62.6$ & $6.59 \pm 1.03$ \\
\hline & 100 & $1.07 \pm 0.38$ & $14.2 \pm 0.2$ & $299.5 \pm 17.0$ & $2.34 \pm 0.11$ \\
\hline
\end{tabular}

ported as a plasticizer, increasing the ductility of these type the polymers. ${ }^{33}$

Studies performed by Kowalski and colleagues ${ }^{46}$ have helped to determine $25 \mathrm{kGy}$ as the standard radiation dose for $\gamma$-radiation. However, even using this dose, effects in the bulk structure of different materials have been reported. ${ }^{31,46-48}$ In the herein studied $\beta$-radiation doses, the maximum decrease in modulus obtained was $13 \%$ after an exposure to the maximum dose of $100 \mathrm{kGy}$, which is four times higher than the recommended dose for $\gamma$-radiation. For the recommended dose ( $25 \mathrm{kGy}$ ), no significant change in the stiffness of SEVA-C is observed. These observations clearly indicate a negligible effect of $\beta$-radiation on bulk stiffness of the SEVA-C samples when applied under the typical radiation dosages of $\gamma$-radiation. Even though a decrease in ductility is observed upon $\beta$-radiation, these results are still attractive as it shows possible to sterilize the material without inducing any severe modifications of its bulk properties. Although $\beta$-radiation relies on the same basic principles as $\gamma$-radiation, the two methods differ in their interaction with matter. While $\gamma$-rays are characterized by high penetration and low dose rate, $\beta$-radiation is characterized by low penetration and high dose rate, ${ }^{49}$ which may justify the obtained differences in the mechanical behavior.
For SCA, an enhancement in both the stiffness and the strength occurs for increasing $\beta$-radiation doses. This different behavior for SCA as compared to SEVA-C may be intimately related to the different nature and chemistry of the two blends. In fact, SEVA-C is an interpenetrated network (IPN) composed by starch and ethylene-vinyl alcohol copolymer (50/50 wt \%), while SCA is a nonmiscible blend composed of starch and cellulose acetate $(50 / 50 \mathrm{wt} \%)$. In the case of SCA, the $\beta$-radiation may induce more extensively free radical formation and crosslinking of both natural polymers, which can ultimately lead to their degradation of the material for high radiation levels. It is important to note that in spite of an increase in both stiffness and strength occurs with increasing $\beta$-radiation doses up to $50 \mathrm{kGy}$, a continuous decrease in ductility and toughness is observed upon $\beta$-radiation, which may be an indication of a possible competing phenomenon between crosslinking and blend degradation. However, these statements will require further chemical and structural characterization to support them. In spite of that, the observed variations in mechanical performance anticipate some variation in the degradation behavior of SCA for different $\beta$-radiation doses.

The exposure of SPCL to $\beta$-radiation causes its stiffening and a strong decrease of the respective ductility. For the
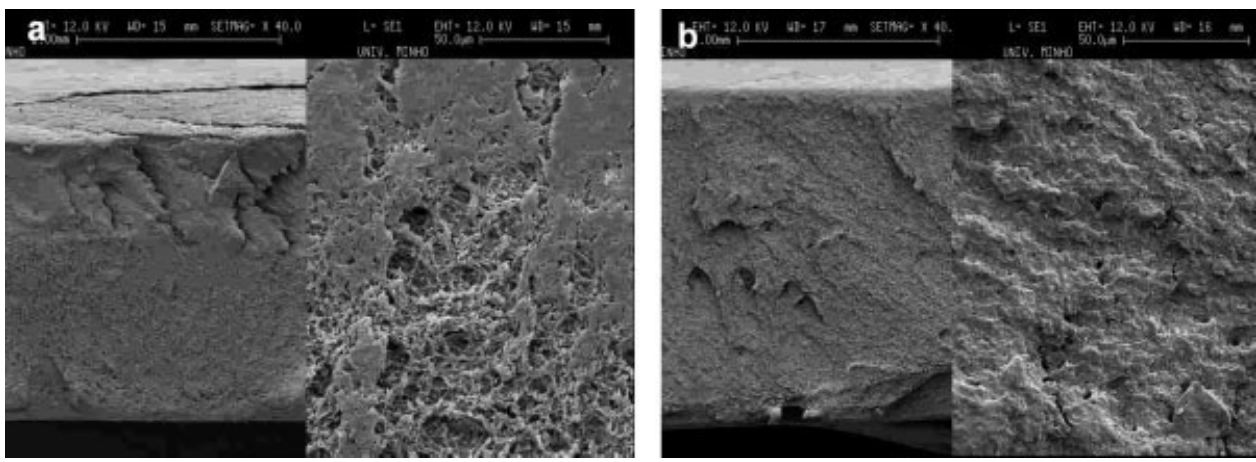

Figure 1. SEM micrographs of the fracture surfaces of SEVA-C (a) before and (b) after $\beta$-sterilization, using a radiation dose of $100 \mathrm{kGy}$. 

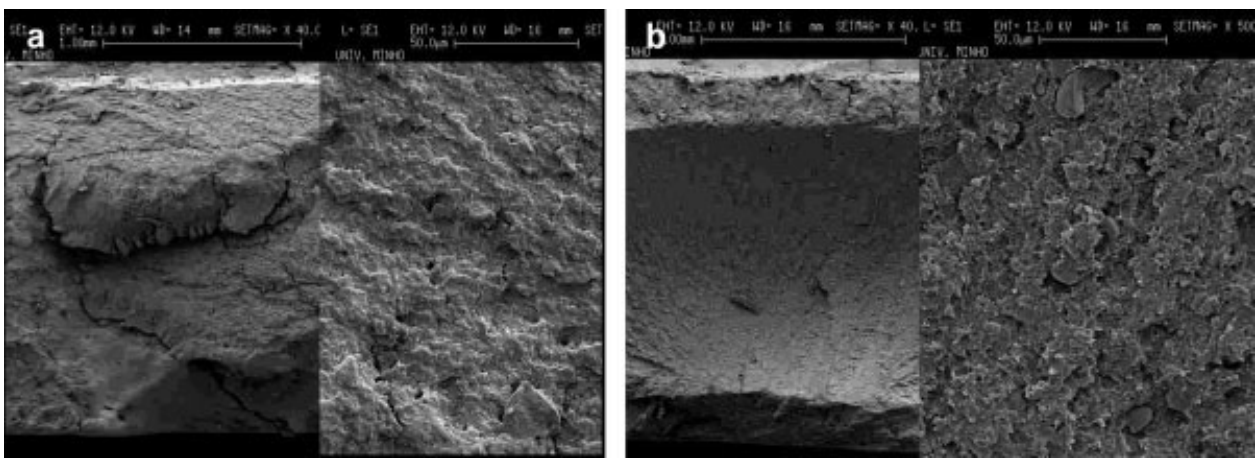

Figure 2. SEM micrographs of the fracture surfaces of SCA (a) before and (b) after $\beta$-sterilization, using a radiation dose of $100 \mathrm{kGy}$.

highest dose, the influence of the $\beta$-radiation is evident. These results emphasize once more the importance of the nature and chemistry of the blend on the effect of radiation dose on mechanical properties. SPCL can be regarded as an homogeneous compatible blend of starch with poly(caprolactone) (PCL; 30/70 wt \%), where poly(caprolactone) is believed to play a prominent role. The variation in mechanical behavior may suggest a similar molecular mechanism for SPCL upon radiation as that proposed for SCA based on the free radical formation and occurrence of crosslinking and/or molecular degradation. In this respect the poly(caprolactone) fraction is assumed to play an important role, as the decrease in toughness observed for SPCL upon radiation dose is consistent with an embrittlement of the blend, which could hardly be explained with structure variations within the starch faction exclusively. This variation may be largely dominated by structure variations within the much more crystalline synthetic phase. This stiffening effect is consistent with the mechanical dynamical analysis (DMA) results and is believed to be dominated by an eventual decrease in crystallinity of the poly(caprolactone) phase arisen due to crosslinking and degradation competing phenomena.

\section{SEM Analysis of Tensile Fracture Surfaces}

The morphology of the surface fractures produced during the tensile tests performed on the materials before and after exposure to the different $\beta$-radiation doses was analysed by SEM. Figures 1 to 3 present the morphology of fracture surfaces before sterilization and after exposing the samples to a radiation dose of $100 \mathrm{kGy}$. By this technique is clearly not possible to observe any large differences in the fracture surfaces of both SEVA-C and SCA (Figures 1 and 2, respectively), as function of the radiation dose. However, for SPCL some differences in the fracture behavior are observable (Figure 3). SPCL usually exhibits necking during plastic deformation with significant fibril formation, as it can be seen from Figure 3(a). This deformation behavior is slightly altered upon $\beta$-radiation exposure: the necking of SPCL still occurs but without signs of extended fibril formation [Figure 3(b)].

\section{DMA Analysis}

Dynamic mechanical analysis (DMA) has been shown by our group to be an adequate technique for the solid-state rheological characterization of new biomaterials. ${ }^{9,50,51}$ In this work both the storage modulus, $E^{\prime}$, and the loss factor, $\tan \delta$, were monitored as a function of the temperature for the different materials, subjected to the different $\beta$-radiation doses. The corresponding thermograms are shown in Figures 4 to 6 .

For all materials $\tan \delta$ is found to vary around 0.1 , near body temperature, which indicates that such systems are able
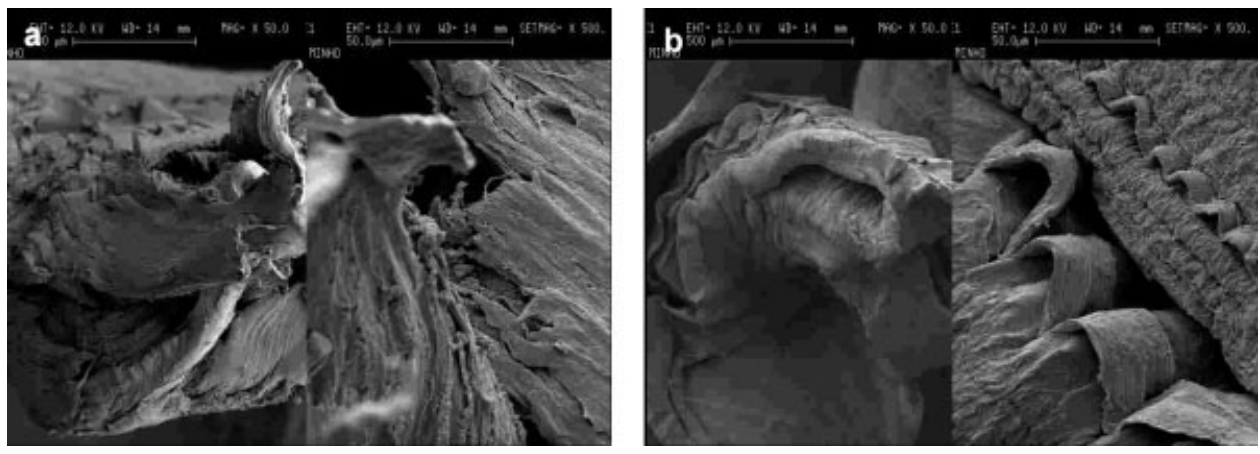

Figure 3. SEM micrographs of the fracture surfaces of SPCL (a) before and (b) after $\beta$-sterilization, using a radiation dose of $100 \mathrm{kGy}$. 


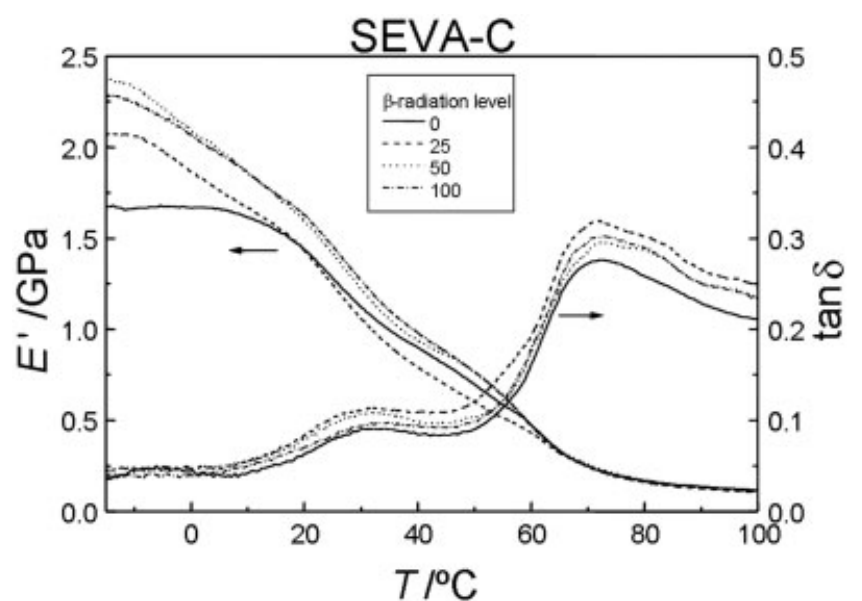

Figure 4. DMA spectrum of SEVA-C before and after being submitted to different doses of $\beta$-radiation.

to dissipate a significant fraction of imposed mechanical energy. The values of $E^{\prime}$ at room temperature are also of the same order of magnitude of the e-modulus (Table I).

SEVA-C presents the most complex behavior among the studied materials. Two clear relaxation processes may be detected in the temperature range analyzed, that contribute for deeper decreases of stiffness during heating. The process at $\sim 30^{\circ} \mathrm{C}$ has been assigned to the dynamic glass transition of the ethylene-vinyl alcohol copolymer fraction (being specially adequate for dissipating energy near physiological temperature), and the process at $\sim 70^{\circ} \mathrm{C}$ was ascribed to molecular motions within the starch fraction. ${ }^{51,52}$ The higher temperature peak is also detected in SCA (Figure 5). No appreciable changes are found in the DMA thermogram of SEVA-C. Due to the heterogeneous character of such blends, significant variations are found when one repeats DMA experiments on the same material. Such fluctuations are of the order of the ones observed in the materials that where previously subjected to different levels of $\beta$-radiation.

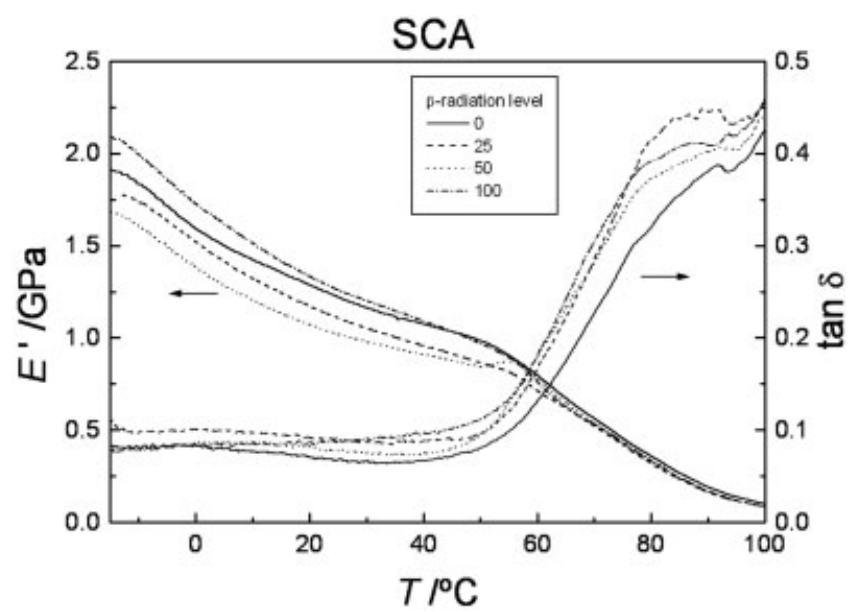

Figure 5. DMA spectrum of SCA before and after being submitted to different doses of $\beta$-radiation.

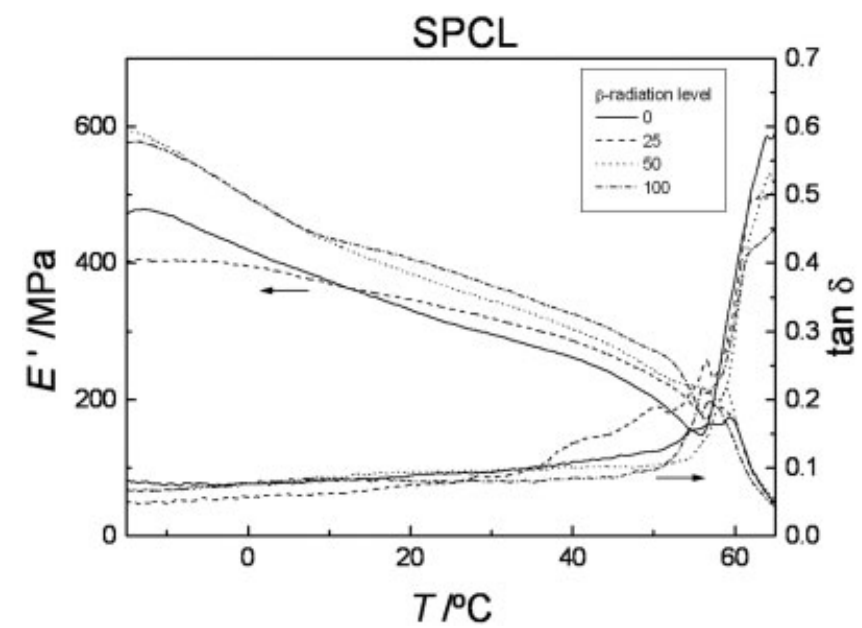

Figure 6. DMA spectrum of SPCL before and after being submitted to different doses of $\beta$-radiation.

No appreciable variations are again found in the viscoelastic properties of the SCA biomaterials upon being subjected to $\beta$-radiation. One may be tempted herein to ascribe a tendency for increasing $\tan \delta$ with increasing radiation dose.

Regarding the SPCL materials, a peak at $\sim 80^{\circ} \mathrm{C}$ is not detectable because the poly(caprolactone) melts at $\sim 60^{\circ} \mathrm{C}$, preventing the DMA study towards higher temperatures. As the glass transition of the synthetic polymer is ca. $-35^{\circ} \mathrm{C}$, this process is not visible in the studied temperature window. The storage modulus lines $\left(E^{\prime}\right)$ appear to indicate that materials stiffen when subjected to $\beta$-radiation. This result is consistent with the previously presented tensile test results (Table I) and respective SEM micrographs of the fracture surfaces (Figure 3).

\section{Water-Uptake Ability}

Water-uptake studies can give valuable information on the behavior of a biodegradable material in the presence of the body fluids. Figures 7 to 9 show the water-uptake behavior of the materials submitted to different doses of $\beta$-radiation,

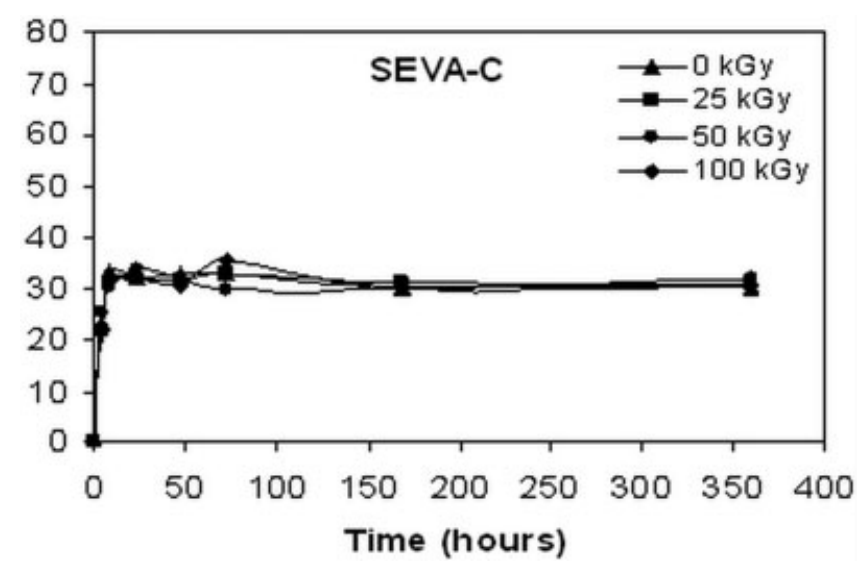

Figure 7. Water uptake of SEVA-C submitted to different doses of $\beta$-radiation. 


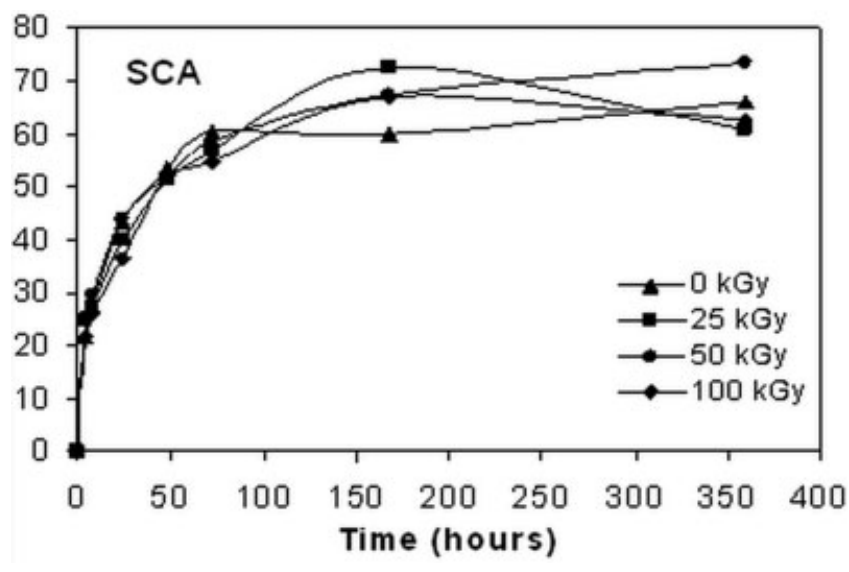

Figure 8. Water uptake of SCA submitted to different doses of $\beta$-radiation.

calculated from water-uptake experiments that last up to 15 days.

The degree of equilibrium hydration varies for each type of material. The different results for the degrees of hydration may result from a conjugated effect of: (i) different amounts of starch hydroxyl groups for each material (SEVA-C contains 50\% of starch, SCA 50\%, and SPCL 30\%); (ii) the different hydrophobic/hydrophilic character of the polymers blended with starch in each material; (iii) the type of structure exhibited by each blend. In the case of SEVA-C and SCA, because the amount of starch in the structure is the same, the differences in the degree of hydration may be related with the type of structure that for SEVA-C is an interpenetrated network while in case of SCA is a nonmiscible blend. Consequently, SCA structure is more favorable for water molecules to be absorbed. In case of SPCL, the low degree of hydration can be justified by the presence of lower amounts of starch in the structure and by the hydrophobic character exhibited by the poly(caprolactone).

There is no significant change in the swelling ability of SEVA-C with increasing doses of $\beta$-radiation. In the case of

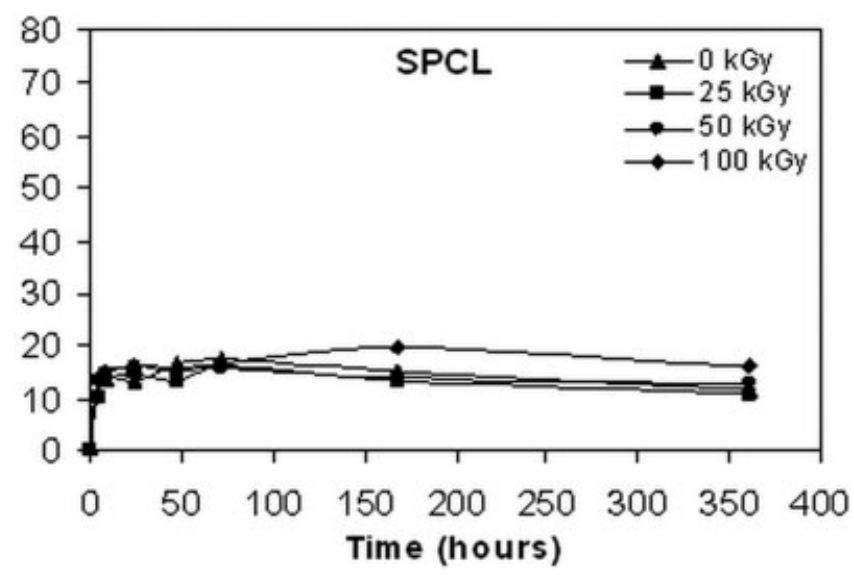

Figure 9. Water uptake of SPCL submitted to different doses of $\beta$-radiation.

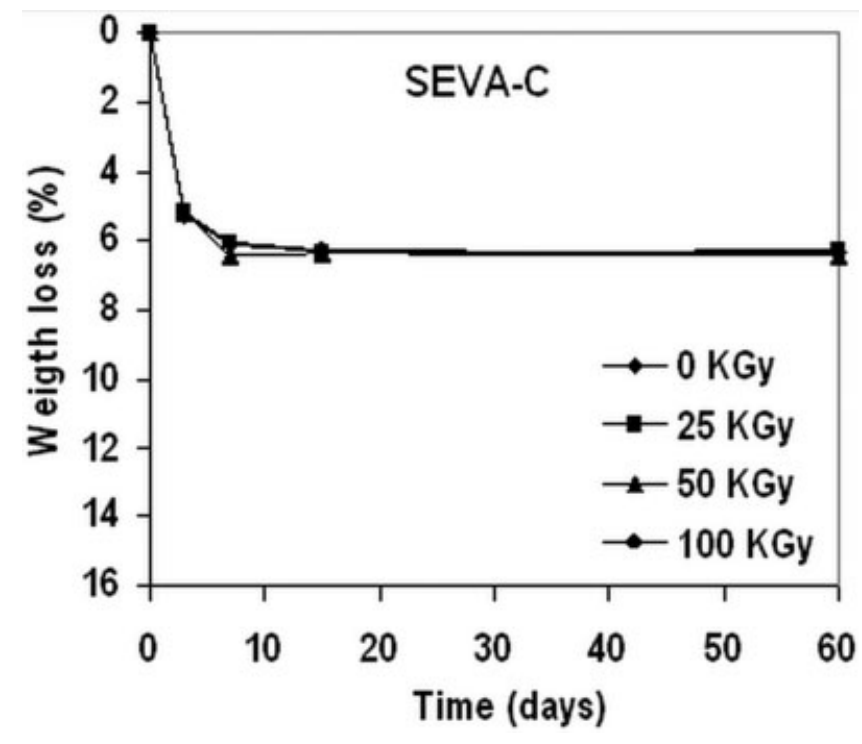

Figure 10. Degradation behavior of SEVA-C with increasing doses of $\beta$-radiation.

SCA and SPCL (Figures 8 and 9), there is some increase in the degree of hydration for the higher doses of radiation.

\section{Degradation Behavior}

Together with the water-uptake studies, the degradation tests are also very important for predicting the lifetime of a biodegradable polymer when implanted. Figures 10 to 12 show the weight loss of SEVA-C, SCA, and SPCL materials in an isotonic saline solution at $37^{\circ} \mathrm{C}$ with immersion time up to 60 days. The differences in the weight loss for each material can be justified by the influence of the same factors that justify the differences in the water-uptake ability, as it has been previously described.

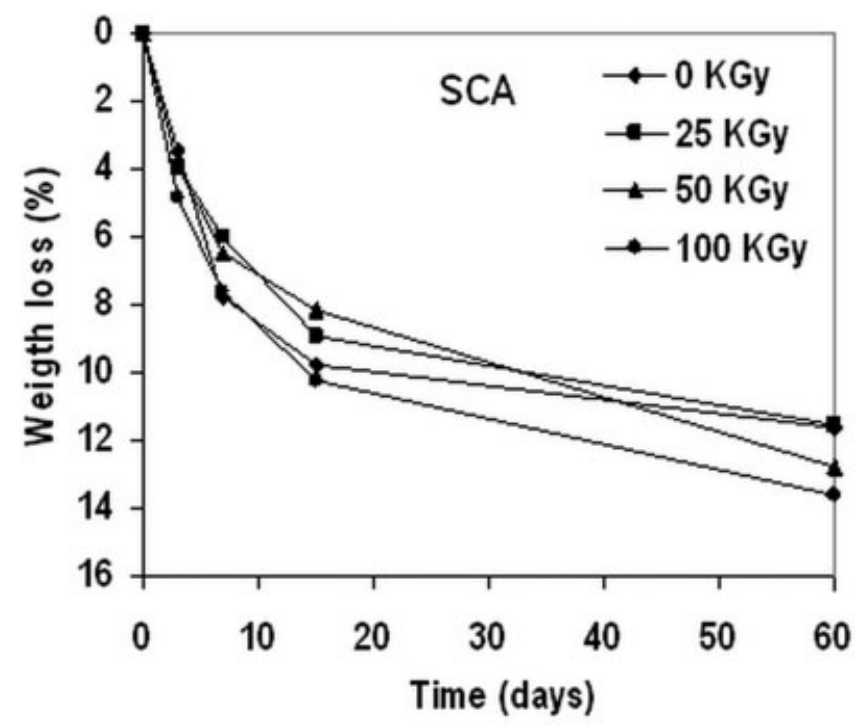

Figure 11. Degradation behavior of SCA with increasing doses of $\beta$-radiation. 
Figure 10 presents the characteristic degradation profile of SEVA-C material. The amount of weight loss with immersion time was not affected by the radiation doses applied as expected from the results obtained by tensile testing and DMA analysis. For SCA samples (Figure 11), it is possible to observe some increase in the weight loss with increasing doses of radiation, indicating that some degradation is taking place. This increase is more evident after 1 week of immersion in the isotonic saline solution. In case of SPCL (Figure 12), after just 3 days of immersion in the isotonic salt solution, it was possible to observe some increase in the weight loss with increasing doses of radiation indicating that a degradation process is also taking place.

\section{Contact-Angle Measurements}

Contact-angle measurements were obtained in order to study the wettability of the different surfaces with increasing doses of $\beta$-radiation. Figure 13 represents the water contact angles measured on the different surfaces by the sessile drop technique (using water as testing liquid).

After a $25 \mathrm{kGy}$ dose of radiation, all the materials seem to show a decrease in the contact angle that resulted from an increase in the hydrophilicity of the surfaces. This is particularly evident in case of SCA and SPCL. For radiation doses higher than $25 \mathrm{kGy}$, the contact angle was not significantly affected, which indicates only $25 \mathrm{kGy}$ are sufficient to induce the modification in the surface. Although the swelling ability of the polymers was not greatly affected by $\beta$-radiation, this sterilization method was able to modify the surface by increasing its hydrophilicity. In this way, if we can consider $\beta$-radiation as a sterilization method that does not affect significantly the mechanical properties and degradation behavior of the materials, we can also see it as an effective way of modifying the surface for applications where hydrophilic surfaces are desirable. Examples of such applications are

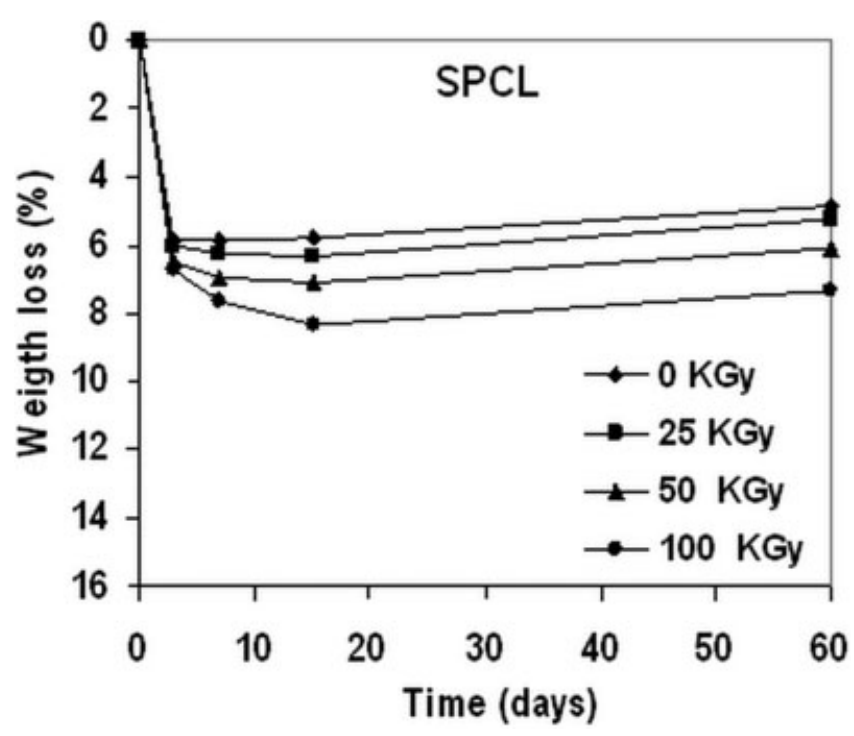

Figure 12. Degradation behavior of SPCL with increasing doses of $\beta$-radiation.

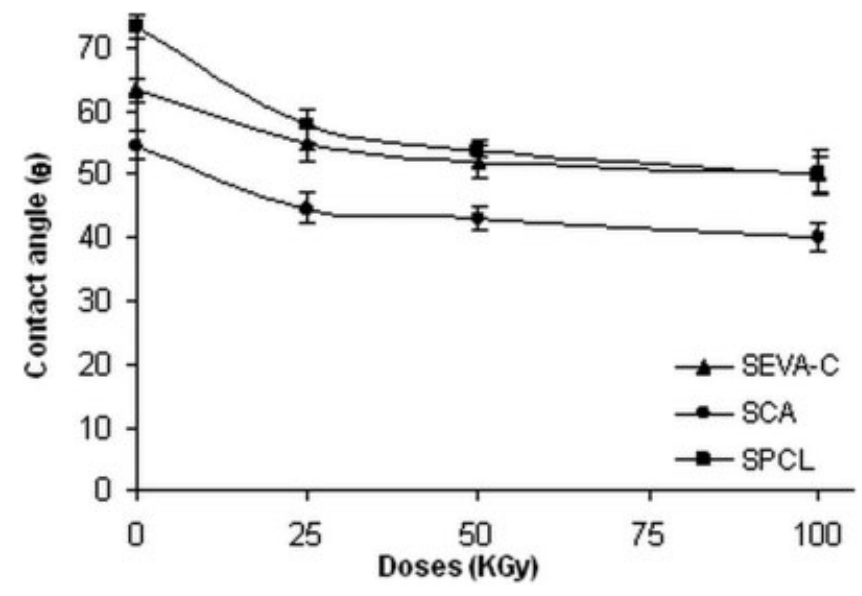

Figure 13. Evolution of the water contact angle with $\beta$-radiation doses for the different materials.

surface treatments to enhance cell adhesion and proliferation, and to induce bioactivity as shown in some of our previous works. $^{53}$

\section{CONCLUSIONS}

The main effect of the sterilization method with $\beta$-radiation over the starch-based polymers seems to be a surface modification by an increase of the hydrophilicity. However, SCA and SPCL seem to exhibit both higher water-uptake ability and weight loss for the higher doses of radiation, possibly due to some degradation of the polymeric structure. Nevertheless, because $\beta$-radiation did not significantly affect the mechanical properties, it can be regarded as an effective way of modifying the surface for applications where more hydrophilic surfaces are desirable.

IonMed Esterilizacion, SA, is acknowledged for performing $\beta$-radiation sterilization.

\section{REFERENCES}

1. Galliard T. Starch: properties and potential. New York: Wiley; 1987.

2. Poutanen K, Forssell P. Modification of starch properties with plasticizers. Trends Polym Sci 1996;4:128-132.

3. Andreopoulos AG, Theophanides T. Degradable plastics - a smart approach to various applications. J Elastomers Plastics 1994;26:308-326.

4. Gomes ME, Reis RL, Cunha AM, Blitterswijk CA, de Bruijn JD. Cytocompatibility and response of osteoblastic-like cells to starch-based polymers: effect of several additives and processing conditions. Biomaterials 2001;22:1911-1917.

5. Marques AP, Reis RL, Hunt JA. The biocompatibility of novel starch-based polymers and composites: in vitro studies. Biomaterials 2002;23:1471-1478.

6. Mendes SC, Reis RL, Bovell YP, Cunha AM, van Blitterswijk CA, de Bruijn JD. Biocompatibility testing of novel starchbased materials with potential application in orthopaedic surgery: a preliminary study. Biomaterials 2001;22:2057-2064. 
7. Reis RL, Cunha A. M. Characterization of two biodegradable polymers of potential application within the biomaterials field. J Mater Sci: Mater Med 1995;6:786-792.

8. Reis RL, Cunha AM, Allan PS, Bevis MJ. Mechanical behavior of injection-molded starch-based polymers. Polym Adv Technol 1996;7:784-790.

9. Elvira C, Mano JF, San Roman J, Reis RL. Starch-based biodegradable hydrogels with potential biomedical applications as drug delivery systems. Biomaterials 2002;23:1955-1966.

10. Pereira CS CAM, Reis RL, Vazquez B, San Roman J. New starch-based thermoplastic hydrogels for use as bone cements or drug-delivery carriers. J Mater Sci: Mater Med 1998;9:825833.

11. Espigares I, Elvira C, Mano JF, Vazquez B, San Roman J, Reis RL. New partially degradable and bioactive acrylic bone cements based on starch blends and ceramic fillers. Biomaterials 2002;23:1883-1895.

12. Gomes ME, Ribeiro AS, Malafaya PB, Reis RL, Cunha AM. A new approach based on injection moulding to produce biodegradable starch-based polymeric scaffolds: morphology, mechanical and degradation behavior. Biomaterials 2001;22:883889.

13. Gomes ME, Godinho JS, Tchalamov D, Cunha AM, Reis RL. Alternative tissue engineering scaffolds based on starch: processing methodologies, morphology, degradation and mechanical properties. Mater Sci Eng C 2002;20:19-26.

14. Malafaya PB, Elvira C, Gallardo A, San Roman J, Reis RL. Porous starch-based drug delivery systems processed by a microwave route. J Biomater Sci Polym Ed 2001;12:1227-1241.

15. Malafaya PB, Gomes ME, Salgado AJ, Reis RL. Polymer based scaffolds and carriers for bioactive agents from different natural origin materials. Tissue Eng 2003;534:201-233.

16. Reis RL, Cunha AM. Characterization of two biodegradable polymers of potential application within the biomaterials field. J Mater Sci: Mater Med 1995;6:786-792.

17. Demirgoz D, Elvira C, Mano JF, Cunha AM, Piskin E, Reis RL. Chemical modification of starch based biodegradable polymeric blends: effects on water uptake, degradation behavior and mechanical properties. Polym Degrad Stab 2000;70:161-170.

18. Reis RL, Cunha AM, Bevis MJ. Oriented composites meet tough orthopedic demands. Modern Plastics 1999;76:73-75.

19. Sousa RA, Reis RL, Cunha AM, Bevis MJ. Processing and properties of bone-analogue biodegradable and bioinert polymeric composites. Compos Sci Technol 2003;63:389-402.

20. Reis RL, Cunha AM, Allan PS, Bevis MJ. Structure development and control of injection-molded hydroxylapatite-reinforced starch/EVOH composites. Adv Polym Technol 1997;16: 263-277.

21. Sousa RA, Mano JF, Reis RL, Cunha AM, Bevis MJ. Mechanical performance of starch based bioactive composite biomaterials molded with preferred orientation. Polym Eng Sci 2002; 42:1032-1045.

22. Sousa RA, Oliveira AL, Reis RL, Cunha AM, Bevis MJ. Bicomposite sandwich moldings: processing, mechanical performance and bioactive behavior. J Mater Sci: Mater Med 2003; 14:385-397.

23. Leonor IB, Sousa RA, Cunha AM, Reis RL, Zhong ZP, Greenspan D. Novel starch thermoplastic/Bioglass ${ }^{\circledR}$ composites: mechanical properties, degradation behavior and in-vitro bioactivity. J Mater Sci: Mater Med 2002;13:939-945.

24. Leonor IB, Ito A, Onuma K, Kanzaki N, Zhong ZP, Greenspan $\mathrm{D}$, Reis RL. In situ study of partially crystallized Bioglass and hydroxylapatite in vitro bioactivity using atomic force microscopy. J Biomed Mater Res 2002;62:82-88.

25. Sousa RA, Kalay G, Reis RL, Cunha AM, Bevis MJ. Injection molding of a starch/EVOH blend aimed as an alternative biomaterial for temporary applications. J Appl Polym Sci 2000;77: 1303-1315.
26. Reis RL, Cunha, A. M., Fernandes, M. H., Correia, R. N Treatments to induce the nucleation and growth of apatite like layers onto polymeric surfaces and foams. J Mater Sci: Mater Med 1997;8:897.

27. Oliveira AL, Elvira C, Reis RL, Vazquez B, San Roman J. Surface modification tailors the characteristics of biomimetic coatings nucleated on starch-based polymers. J Mater Sci: Mater Med 1999;10:827-835.

28. Oliveira AL, Malafaya PB, Reis RL. Sodium silicate gel as a precursor for the in vitro nucleation and growth of a bone-like apatite coating in compact and porous polymeric structures. Biomaterials 2003;24:2575-2584.

29. Leonor IB, Reis RL. An innovative auto-catalytic deposition route to produce calcium-phosphate coatings on polymeric biomaterials. J Mater Sci: Mater Med 2003;14:435-441.

30. Matthews IP, Gibson C, Samuel AH. Sterilisation of implantable devices. Clin Mater 1994;15:191-215.

31. Kowalski JB, Morrissey RF. Sterilization of implants. In: Ratner BD, Hoffman AS, Schoen FJ, Lemnons JE, editors. Biomaterials science. San Diego: Academic Press; 1996. p 415-422.

32. Hartman LC, Meenaghan MA, Schaaf NG, Hawker PB. Effects of pretreatment sterilization and cleaning methods on materials properties and osseoinductivity of a threaded implant. Int J Oral Maxillofac Implants 1989;4:11-18.

33. Reis RL, Mendes SC, Cunha AM, Bevis MJ. Processing and in vitro degradation of starch/EVOH thermoplastic blends. Polym Int 1997;43:347-352.

34. Oliveira AL, Elvira C, Vasquez B, San Roman J, Reis RL. Surface modifications tailors the characteristics of biomimetic coatings nucleated on starch based polymers. J Mater Sci: Mater Med 1999;10:827.

35. Hastings CE, Martin SA, Heath JR, Mark DE, Mansfield JL, Hollinger JO. The effects of ethylene-oxide sterilization on the in vitro cytotoxicity of a bone-replacement material. Toxicol In Vitro 1990;4:757-762.

36. Hogstedt C, Rohlen O, Berndtsson BS, Axelson O, Ehrenberg L. Cohort study of mortality and cancer incidence in ethyleneoxide production workers. Br J Industr Med 1979;36:276-280.

37. Morrissey RF, Herring CM. Radiation sterilization: past, present and future. Radiat Phys Chem 2002;63:217-221.

38. Nuutinen JP, Clerc C, Virta T, Tormala P. Effect of gamma, ethylene oxide, electron beam, and plasma sterilization on the behavior of SR-PLLA fibres in vitro. J Biomater Sci Polym Ed 2002;13:1325-1336.

39. Henn GG, Birkinshaw C, Buggy M, Jones E. A comparison of the effects of gamma-irradiation and ethylene oxide sterilization on the properties of compression moulded poly-d,l-lactide. J Mater Sci: Mater Med 1996;7:591-595.

40. Ciesla K, Eliasson A-C. Influence of gamma radiation on potato starch gelatinization studied by differential scanning calorimetry. Radiat Phys Chem 2002;64:137-148.

41. Hayashi T, Kawashima K. The effect of gamma-irradiation on the sucrose content in qweet-potato roots and potato-tubers. Agric Biol Chem 1982;46:1475-1479.

42. Michel JP, Raffi J, Saintlebe L. Experimental study of the radiodepolymerization of starch. Starke 1980;32:295-298.

43. Ciesla K, Zoltowski T, Diduszko R. Physicochemical changes occurring in gamma-irradiated flours studied by small-angle X-ray-scattering. Food Struct 1993;12:175-180.

44. Woo L, Sandford CL. Comparison of electron beam irradiation with gamma processing for medical packaging materials. Radiat Phys Chem 2002;63:845-850.

45. Ferry JD. Viscoelastic properties of polymers. New York: Wiley; 1980.

46. Kowalski JB, Yan AS, Tallentire A. Radiation sterilization evaluation of a new approach for substantiation of $25 \mathrm{kGy}$. Radiat Phys Chem 2000;58:77-86. 
47. Benson RS. Use of radiation in biomaterials science. Nucl Instrum Meth Phys Res Sect B 2002;191:752-757.

48. Kowalski JB, Tallentire A. Substantiation of $25 \mathrm{kGy}$ as a sterilization dose: a rational approach to establishing verification dose. Radiat Phys Chem 1999;54:55-64.

49. Sintzel MB, Schwach-Abdellaoui K, Mader K, Stosser R, Heller J, Tabatabay C, Gurny R. Influence of irradiation sterilization on a semi-solid poly(ortho ester). Int J Pharm 1998;175:165176.

50. Mano JF, Vaz CM, Mendes SC, Reis RL, Cunha AM. Dynamic mechanical properties of hydroxyapatite-reinforced and porous starch-based degradable biomaterials. J Mater Sci: Mater Med 1999;10:857-862.
51. Mano JF, Reis RL, Cunha AM. Effects of moisture and degradation time over the mechanical dynamical performance of starch-based biomaterials. J Appl Polym Sci 2000;78:23452357.

52. Mano FJ, R.L. Reis, A.M.Cunha. Dynamic mechanical analysis in polymers for medical applications. In: Reis RL, Cohn D, editors. Polymer based systems on tissue engineering, replacement and regeneration. Dordrecht: Kluwer Academic Publishers; 2002. p 139-164.

53. I. Pashkuleva, Marques AP, Vaz F, Reis RL. Surface modification of starch based blends using potassium permanganate-nitric acid system and its effect on the adhesion and proliferation of osteoblast-like cells. J Mater Sci: Mater Med 2005;16:81-92. 